\title{
Chiral Bis-pyridinium Salts as Novel Stereoselective Catalysts for the Metal-Free Diels-Alder Cycloaddition of $\alpha, \beta$-Unsaturated Aldehydes
}

\author{
Andrea Genoni, Maurizio Benaglia,* Alessandra Puglisi, Sergio Rossi \\ Dipartimento di Chimica Organica e Industriale, Università degli Studi di Milano, via Golgi 19, 20133 Milano, Italy \\ Fax+39(02)50314159; E-mail: maurizio.benaglia@unimi.it \\ Received 21 March 2011
}

\begin{abstract}
The synthesis of enantiomerically pure $C_{2}$-symmetric bis-pyridinium salts was realized through a simple condensation of 2-pyridyl-carboxyaldehydes with a chiral diamine. The catalytic properties of such novel compounds were preliminarily studied and the trifluoracetate salts of chiral bis-imines of 2-picolinaldehydes derived from 1,1'-binaphthyl-2,2'-diamine were shown to catalyze the Diels-Alder reaction between cyclopentadiene and $\alpha, \beta$-unsaturated aldehydes. Modest exo stereoselectivities and enantioselectivities of up to $55 \%$ were obtained.
\end{abstract}

Key words: chiral imines, Diels-Alder reaction, pyridinium salt, enantioselective catalysis, hydrogen bonding activation

The development of novel methodologies for the preparation of enantiomerically pure compounds is a very active topic of great interest for several fields, such as agrochemicals, flavor and aroma chemicals, pharmaceuticals, and specialty materials. ${ }^{1}$ A fundamental reaction that allows $\mathrm{C}-\mathrm{C}$ bonds to be built stereoselectively is the Diels-Alder reaction, which enables the preparation of stereochemically well-defined polyfunctional derivatives. ${ }^{2}$

In the last few years, great attention has been devoted to the exploration of new catalytic methodologies that involve the use of organocatalysts. ${ }^{3}$ In this context, the use of 'metal-free' chiral catalysts that are able to promote highly stereoselective cycloaddition reactions has offered a novel, complimentary, powerful approach that has opened the way to new, valuable, chiral intermediates. ${ }^{4 a}$ Lelais and MacMillan established that both Diels-Alder reactions and 1,3-dipolar cycloadditions can be catalyzed using chiral amino acid derived imidazolidinones as catalysts, and that these catalysts were able to promote the generation of an iminium ion in situ from a carbonyl compound. $^{4 \mathrm{~b}}$

However, the search for alternative modes of activation is still very active. It has been recently recognized that the use of hydrogen bonding to activate a suitably functionalized substrate may represent a viable alternative to traditional methodology that relies upon Lewis acid catalysis. ${ }^{5}$ Among the range of chiral compounds capable of donating one or more hydrogen bonds and, consequently, able to catalyze stereoselective reactions, phosphoric acids, ${ }^{6}$ diols, ${ }^{7}$ thiourea ${ }^{8}$ derivatives, more recently squaramides ${ }^{9}$ and, less often, carboxylic acids, ${ }^{10}$ have been widely used.

SYNTHESIS 2011, No. 12, pp 1926-1929

Advanced online publication: 13.05.2011

DOI: 10.1055/s-0030-1260462; Art ID: C00511SS

(c) Georg Thieme Verlag Stuttgart · New York
However, of the reactions studied, ${ }^{11}$ only a few examples of hetero-Diels-Alder reactions were reported to be catalyzed by phosphoric acids ${ }^{12}$ or Taddol-type derivatives; ${ }^{13}$ furthermore, to the best of our knowledge, no example of hydrogen-bond-activation of substrates for Diels-Alder cycloadditions has been reported. ${ }^{14}$

We have recently demonstrated that trifluoroacetate salts of enantiomerically pure bis-amines may be used to catalyze the stereoselective Diels-Alder cycloaddition of cyclopentadiene to cinnamaldehyde and crotonaldehyde with good exo stereoselectivity and enantioselectivities up to $71 \% .^{15}$

Because of our interest in developing novel metal-free chiral catalysts for hydrogen-bond-promoted reactions, ${ }^{16}$ we decided to investigate the use of enantiomerically pure bis-pyridinium salts derived from picolinic aldehyde as catalysts for the Diels-Alder reaction between cyclopentadiene and $\alpha, \beta$-unsaturated aldehydes. We wish to report here the results of our preliminary studies in the field.

In our study, we wanted to obtain chiral organocatalysts by simple reaction of an inexpensive, commercially available, enantiopure material, and to keep the amount of required manipulation to a minimum. Indeed, several derivatives were synthesized in a single-step procedure by reaction of a range of enantiomerically pure diamines (1,1'-binaphthyl-2,2'-diamine, 1,2-diamino cyclohexane, or 1,2-diphenyl ethylendiamine) with 2-picolinic aldehyde (compounds 1, 2, 6, and 7) or 2-picolinic acid (compounds 3, 4, 8, and 9). For comparison, bis-imine 5, derived from 3-pyridinecarboxyaldehyde, was also prepared (Figure 1).

Preliminary studies on the catalytic properties of the synthesized compounds were performed. The trifluoroacetate salts of compounds 1-9 were prepared and tested as organic catalysts in the enantioselective Diels-Alder reaction between cyclopentadiene and cinnamaldehyde (Scheme 1).

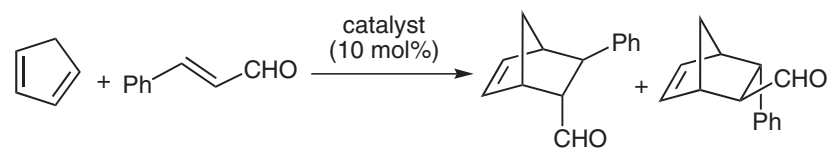

Scheme 1 Stereoselective organocatalyzed Diels-Alder reaction

In a typical experimental procedure, the catalysts were prepared by treating the chiral bis-pyridine derivative in 
<smiles>C(=N/c1ccc2ccccc2c1-c1c(/N=C/c2ccccn2)ccc2ccccc12)\c1ccccn1</smiles><smiles>c1ccc(CNc2ccc3ccccc3c2-c2c(NCc3ccccn3)ccc3ccccc23)nc1</smiles>

2<smiles>C(=N/C1CCCC[C@H]1/N=C/c1ccccn1)\c1ccccn1</smiles><smiles>c1ccc(CNC2CCCCC2NCc2ccccn2)nc1</smiles>

7<smiles>[2H]c1ccc2ccccc2c1-c1c(N([2H])C(=O)c2ccccn2)ccc2ccccc12</smiles>

$3 \mathrm{R}=\mathrm{H}$

$4 \mathrm{R}=\mathrm{Me}$<smiles>O=C(N[C@H]1CCCC[C@H]1NC(=O)c1ccccn1)c1ccccn1</smiles>

8<smiles>C(=N/c1ccc2ccccc2c1-c1c(/N=C/c2cccnc2)ccc2ccccc12)\c1cccnc1</smiles>

5<smiles>O=C(N[C@H](c1ccccc1)[C@H](NC(=O)c1ccccn1)c1ccccc1)c1ccccn1</smiles>

9

Figure 1 Novel chiral organocatalysts for stereoselective Diels-Alder cycloaddition

dichloromethane with the required amount of acid and removing the solvent after 15 minutes of stirring at $25^{\circ} \mathrm{C}$; the salt was used without any further purification. ${ }^{17}$ To a stirred solution of the catalyst ( 0.1 equiv) in a suitable solvent (see Table 1 and Table 2) under an inert atmosphere, aldehyde ( 1 equiv) was added; after five minutes, cyclopentadiene ( 5 equiv) was added and the reaction mixture was allowed to stir. The reaction mixture was evaporated under reduced pressure and analyzed by NMR. The yield and diastereoisomeric ratio were then confirmed by analyzing the isolated product after flash chromatography.

Table 1 Diels-Alder Reaction Catalyzed by Compounds 1-9

\begin{tabular}{llllll}
\hline Entry & $\begin{array}{l}\text { Catalyst } \\
(10 \mathrm{~mol} \%)\end{array}$ & $\begin{array}{l}\text { Yield } \\
(\%)^{\mathrm{a}}\end{array}$ & exolendo $^{\mathrm{b}}$ & $\begin{array}{l}\text { ee exo } \\
(\%)^{\mathrm{c}}\end{array}$ & $\begin{array}{l}\text { ee endo } \\
(\%)^{\mathrm{c}}\end{array}$ \\
\hline 1 & $\mathbf{1}$ & $>99$ & $60: 40$ & 55 & 21 \\
2 & $\mathbf{2}$ & 70 & $70: 30$ & 25 & n.d. \\
3 & $\mathbf{3}$ & n.r. & - & - & - \\
4 & $\mathbf{4}$ & n.r. & - & - & - \\
5 & $\mathbf{5}$ & 70 & $50: 50$ & 41 & 11 \\
6 & $\mathbf{6}$ & 47 & $60: 40$ & 25 & 11 \\
7 & $\mathbf{7}$ & 33 & $65: 35$ & 21 & n.d. \\
8 & $\mathbf{8}$ & n.r. & - & - & - \\
9 & $\mathbf{9}$ & n.r. & - & - & - \\
\hline
\end{tabular}

${ }^{\text {a }}$ Reaction was run at $25{ }^{\circ} \mathrm{C}$ for $72 \mathrm{~h}$; the yield was determined by ${ }^{1} \mathrm{H}$ NMR analysis of the crude reaction mixture and confirmed after silica gel flash column purification (n.r. $=$ no reaction).

${ }^{\mathrm{b}}$ Determined by ${ }^{1} \mathrm{H}$ NMR analysis and confirmed by HPLC analysis. ${ }^{\mathrm{c}}$ Determined by HPLC analysis with a chiral stationary phase on the corresponding alcohol (n.d. = not determined).
From this preliminary investigation, bis-imines emerged as the catalysts of choice; these were able to promote the cycloaddition with higher chemical yields than the corresponding bis-amines (Table 1, entries 1 vs. 2 and 6 vs. 7). Chiral bis-imines of 2-pyridine carboxyaldehyde 1, derived from binaphthyl diamine, performed better than the corresponding bis-amines $\mathbf{2}$, leading to the cycloadduct product in quantitative yield and 55\% enantioselectivity for the exo isomer, which is higher than the value obtained with catalyst $\mathbf{2}$. It is noteworthy that the use of chiral bispicolinamides, under the present experimental conditions, was completely ineffective. Bis-imine 5, obtained from 3pyridine carboxyaldheyde, catalyzed the reaction in lower chemical and stereochemical yield. Derivatives of 1,1'-binaphthyl-2,2'-diamine were therefore selected for further optimization studies.

A selection of enantiomerically pure bis-imines were prepared by reaction of 1,1'-binaphthyl-2,2'-diamine with a range of substituted 2-picolinic aldehydes (compounds 10-12, Figure 2), and the enantiomerically pure bis-imine 13, derived from 2-quinoline carboxyaldehyde, was also successfully synthesized. The catalytic activity of the new chiral organocatalysts was then investigated (Table 2, entries 1-5).

From the data collected in Table 2 it is clear that a substituent in the 6-position of the pyridine ring does not significantly affect the stereoselectivity of the process. Almost no diastereoselectivity was observed and the enantioselectivities were generally lower than that obtained with compound $\mathbf{1}$.

With the best performing catalyst $\mathbf{1}$, attempts were made to improve the stereoselectivity by adjusting the experimental conditions and by changing the reaction solvent. 

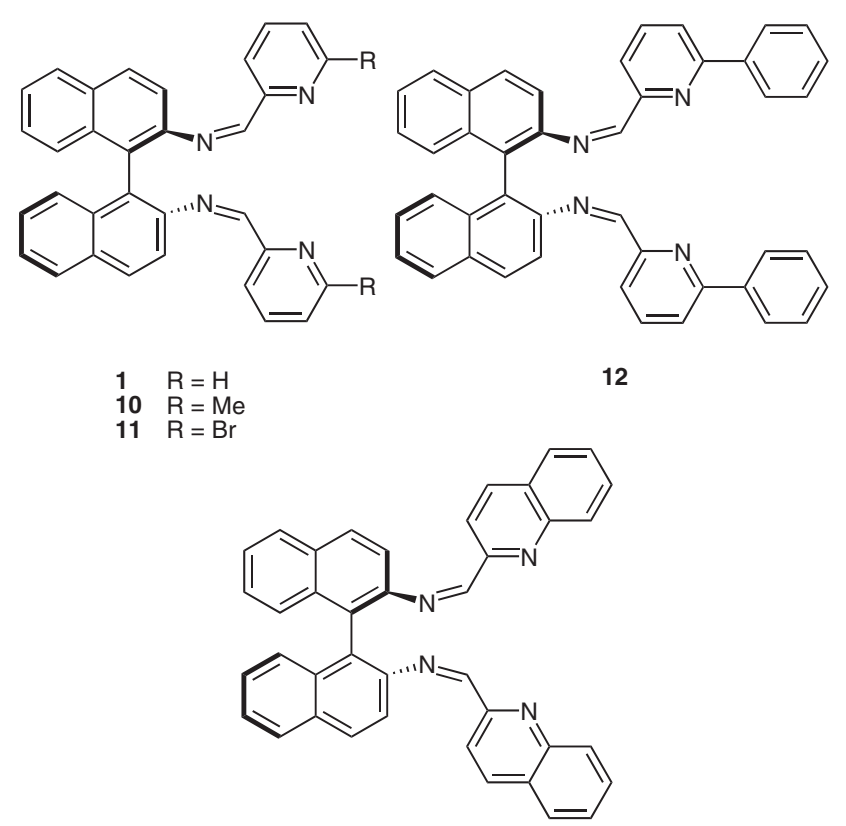

13

Figure 2 Binaphthyl diamine-derived organocatalysts for the Diels-Alder reaction

Table 2 Diels-Alder Reaction Catalyzed by Compounds 1 and 1013

\begin{tabular}{ccccccc}
\hline Entry & Catalyst Solvent & $\begin{array}{l}\text { Yield } \\
(\%)^{\mathrm{a}}\end{array}$ & exolendo $^{\mathrm{b}}$ & $\begin{array}{l}\text { ee exo } \\
(\%)^{\mathrm{c}}\end{array}$ & $\begin{array}{l}\text { ee endo } \\
(\%)^{\mathrm{c}}\end{array}$ \\
\hline 1 & $\mathbf{1}$ & $\mathrm{CHCl}_{3}$ & $>99$ & $60: 40$ & 55 & 21 \\
2 & $\mathbf{1 0}$ & $\mathrm{CHCl}_{3}$ & 53 & $52: 48$ & 45 & 23 \\
3 & $\mathbf{1 1}$ & $\mathrm{CHCl}_{3}$ & 71 & $55: 45$ & 21 & 35 \\
4 & $\mathbf{1 2}$ & $\mathrm{CHCl}_{3}$ & 39 & $55: 45$ & 33 & 15 \\
5 & $\mathbf{1 3}$ & $\mathrm{CHCl}_{3}$ & 91 & $58: 42$ & 21 & 19 \\
$6^{\mathrm{d}}$ & $\mathbf{1}$ & $\mathrm{CHCl}_{3}$ & 87 & $61: 39$ & 45 & 11 \\
$7^{\mathrm{e}}$ & $\mathbf{1}$ & $\mathrm{CH}_{2} \mathrm{Cl}$ & 73 & $62: 38$ & 41 & 21 \\
8 & $\mathbf{1}$ & hexane $_{2}$ & 95 & $51: 49$ & 40 & 14 \\
9 & $\mathbf{1}$ & toluene & 93 & $48: 52$ & 43 & 15 \\
10 & $\mathbf{1}$ & $\mathrm{THF}_{11}$ & 71 & $47: 53$ & 37 & 16 \\
11 & $\mathbf{1}$ & MeCN & 51 & $55: 45$ & 39 & 12 \\
\hline
\end{tabular}

${ }^{\text {a }}$ Reaction was run at $25^{\circ} \mathrm{C}$ for $72 \mathrm{~h}$; the yield was determined by ${ }^{1} \mathrm{H}$ NMR analysis of the crude reaction mixture and confirmed after silica gel flash column purification.

${ }^{\mathrm{b}}$ Determined by ${ }^{1} \mathrm{H}$ NMR analysis and confirmed by HPLC analysis.

${ }^{\mathrm{c}}$ Determined by HPLC analysis on a chiral stationary phase on the corresponding alcohol.

d AcOH was used.

${ }^{\mathrm{e}}$ Reaction performed in 1,2-dichloroethane afforded similar results.
Protic acids other than trifluoroacetic acid were employed, but no improvement in either the chemical or stereochemical yield was observed (Table 2 , entry 6). ${ }^{18}$ Changing the solvent also did not lead to any significant improvement. As expected, best results were obtained in non-polar and non-coordinating solvents, such as hexane or toluene, where the activation of the substrate by the catalyst through hydrogen bonding should work better; however, modest stereoselectivities were obtained even in these cases. ${ }^{19}$

In summary, enantiomerically pure metal-free catalysts for the Diels-Alder reaction have been easily prepared by mixing commercially available chiral diamines and pyridine carboxyaldehyde. The trifluoroacetate salt of chiral bis-imine of 2-picolinaldehyde, derived from 1,1'-binaphthyl-2,2'-diamine, was able to catalyze the Diels-Alder reaction between cyclopentadiene and cinnamaldehyde; modest diastereoselectivities and enantioselectivity of up to $55 \%$ were observed. While the stereoselection of the process is still unsatisfactory and several issues still need to be addressed, we believe the present work may open new perspectives towards the development of organocatalyzed Diels-Alder cycloaddition through hydrogenbond-activation of reaction substrates.

\section{Synthesis of Catalyst; General Procedure}

To a solution of chiral diamine $(10 \mathrm{mmol})$ in anhydrous toluene (20 $\mathrm{mL})$, aromatic aldehyde $(20.2 \mathrm{mmol})$ was added. The mixture was stirred in the presence of $4 \AA$ molecular sieves for $40-72 \mathrm{~h}$ at $110^{\circ} \mathrm{C}$. The reaction mixture was cooled to r.t., filtered and the solvent was evaporated under vacuum to give the corresponding imines in yields $>90 \%$. The bis-imine may be crystallized from ethanol.

\section{Catalyst 1}

${ }^{1} \mathrm{H} \mathrm{NMR}\left(200 \mathrm{MHz}, \mathrm{CDCl}_{3}\right): \delta=8.53(\mathrm{~m}, 2 \mathrm{H}), 8.43(\mathrm{~s}, 2 \mathrm{H}), 8.07$ $(\mathrm{d}, J=8.7 \mathrm{~Hz}, 2 \mathrm{H}), 7.99(\mathrm{~d}, J=8.2 \mathrm{~Hz}, 2 \mathrm{H}), 7.63(\mathrm{t}, J=6.0 \mathrm{~Hz}$, $2 \mathrm{H}), 7.47-7.50(\mathrm{~m}, 4 \mathrm{H}), 7.44(\mathrm{t}, J=6.0 \mathrm{~Hz}, 2 \mathrm{H}), 7.29-7.32(\mathrm{~m}$, $4 \mathrm{H}), 7.17(\mathrm{~d}, J=8.7 \mathrm{~Hz}, 2 \mathrm{H})$.

${ }^{13} \mathrm{C} \mathrm{NMR}\left(50 \mathrm{MHz}, \mathrm{CDCl}_{3}\right): \delta=162.5,155.4,150.6,148.8,137.6$, $132.9,130.3,129.1,127.8,127.6,127.1,126.3,126.2,121.6,119.9$, 118.2 .

\section{Diels-Alder Reaction; General Procedure}

The catalysts were prepared by treating the diamine in anhydrous $\mathrm{CH}_{2} \mathrm{Cl}_{2}(0.5 \mathrm{~mL})$ with the required amount of acid and removing the solvent after 15 min stirring at $25^{\circ} \mathrm{C}$; the salt was used without any further purification. To a stirring solution of catalyst $(0.03 \mathrm{mmol})$ in $\mathrm{CHCl}_{3}(0.3 \mathrm{~mL})$ under an inert atmosphere, aldehyde $(0.3 \mathrm{mmol})$ was added. After $5 \mathrm{~min}$, cyclopentadiene $(1.5 \mathrm{mmol})$ was added and the reaction mixture was allowed to stir for $72 \mathrm{~h}$ at $25^{\circ} \mathrm{C}$. The reaction mixture was evaporated under reduced pressure and analyzed by NMR. The yield and diastereoisomeric ratio were then confirmed with the pure isolated product after flash chromatography on a short silica gel column (EtOAc-hexanes). The enantiomeric excess was determined by HPLC on the alcohol obtained by $\mathrm{NaBH}_{4}$ mediated reduction of the cycloadducts (for exo isomer: Chiralpak OJ-H column; hexane-isopropanol, 7:3; flow rate $0.8 \mathrm{~mL} / \mathrm{min} ; \lambda=$ $225 \mathrm{~nm} ; t_{\text {major }}=38.7 \mathrm{~min}, t_{\text {minor }}=51.8 \mathrm{~min}$ ). 
Supporting Information for this article is available online at http://www.thieme-connect.com/ejournals/toc/synthesis.

\section{Acknowledgment}

This work was supported by MIUR: 'Nuovi metodi catalitici stereoselettivi e sintesi stereoselettiva di molecole funzionali' and CINMPIS (Consorzio Interuniversitario Nazionale Metodologie e Processi Innovativi di Sintesi).

\section{References}

(1) (a) Federsel, H.-J. Drug News Perspect. 2008, 21, 193. (b) See also: Federsel, H.-J. Acc. Chem. Res. 2009, 42, 671; and references cited therein.

(2) (a) Evans, D. A.; Johnson, J. S. In Comprehensive Organic Catalysis; Jacobsen, E. N.; Pfaltz, A.; Yamamoto, H., Eds.; Springer: Berlin, 1999, 1177. (b) Hayashi, Y. In

Cycloaddition Reactions in Organic Synthesis; Kobayashi, S.; Jørgensen, K. A., Eds.; Wiley-VCH: Weinheim, 2002, 5. (c) Kobayashi, S. In Cycloaddition Reactions in Organic Synthesis; Kobayashi, S.; Jørgensen, K. A., Eds.; WileyVCH: Weinheim, 2002, 187.

(3) (a) Pellissier, H. Tetrahedron 2007, 63, 9267.

(b) Enantioselective Organocatalysis. Reactions and Experimental Procedures; Dalko, P. I., Ed.; Wiley-VCH: Weinheim, 2007. For recent reviews, see: (c) Dondoni, A.; Massi, A. Angew. Chem. Int. Ed. 2008, 47, 4638. (d) Melchiorre, P.; Marigo, M.; Carlone, A.; Bartoli, G. Angew. Chem. Int. Ed. 2008, 47, 6138.

(4) (a) For a review, see: Merino, P.; Marqués-López, E.; Tejero, T.; Herrera, R. P. Synthesis 2010, 1. (b) Lelais, G.; MacMillan, D. W. C. Aldrichimica Acta 2006, 39, 79.

(5) For reviews, see: (a) Schreiner, P. R. Chem. Soc. Rev. 2003, 32, 289. (b) Pihko, P. M. Angew. Chem. Int. Ed. 2004, 43, 2062. (c) Doyle, A. G.; Jacobsen, E. N. Chem. Rev. 2007, 107, 5713. (d) Sohtome, Y.; Nagasawa, K. Synlett 2010, 1.
(6) For reviews, see: (a) Akiyama, T.; Itoh, J.; Fuchibe, K. Adv. Synth. Catal. 2006, 348, 999. (b) Connon, S. J. Angew. Chem. Int. Ed. 2006, 45, 3909.

(7) McGilvra, J. D.; Unni, A. K.; Modi, K.; Rawal, V. H. Angew. Chem. Int. Ed. 2006, 45, 6130.

(8) (a) Taylor, M. S.; Jacobsen, E. N. Angew. Chem. Int. Ed. 2006, 45, 1520. (b) Connon, S. J. Chem. Eur. J. 2006, 12, 5418 .

(9) (a) Zhu, Y.; Malerich, J. P.; Rawal, V. H. Angew. Chem. Int. Ed. 2010, 49, 153; and references cited therein. (b) For the first communication, see: Malerich, J. P.; Hagihara, K.; Rawal, V. H. J. Am. Chem. Soc. 2008, 130, 14416.

(10) Hashimoto, T.; Maruoka, K. J. Am. Chem. Soc. 2007, 129, 10054.

(11) Zhang, Z.; Schreiner, P. R. Chem. Soc. Rev. 2009, 38, 1187.

(12) (a) Liu, H.; Cun, L.-F.; Mi, A.-Q.; Jiang, Y.-Z.; Gong, L.-Z. Org. Lett. 2006, 8, 6023. (b) Itoh, J.; Fuchibe, K.; Akiyama, T. Angew. Chem. Int. Ed. 2006, 44, 4796.

(13) Huang, Y.; Unni, A. K.; Thadani, A. N.; Rawal, V. H. Nature 2003, 424, 146.

(14) See examples summarized in ref. $4 a$.

(15) Biaggi, C.; Benaglia, M.; Rossi, S.; Proto, S.; Annunziata, R. Tetrahedron Lett. 2007, 48, 8521.

(16) Guizzetti, S.; Puglisi, A.; Raimondi, L.; Benaglia, M. Synth. Commun. 2009, 39, 3731.

(17) When the reaction was promoted by catalysts generated in situ by mixing the chiral diamine with the required amount of trifluoroacetic acid for $15 \mathrm{~min}$ in the reaction solution before adding the reagents, the formation of the product was observed in only trace amounts.

(18) Among others, triflic acid and benzoic acid were used; with stronger acids, such as $\mathrm{HCl}$, no reaction was observed.

(19) By running the reaction at lower temperature $\left(0^{\circ} \mathrm{C}\right)$, the yields were usually depressed without any positive effect on the stereoselectivity. 